\title{
Quantitative evaluation of deterioration in west wind-room in the Palace Museum
}

\author{
Yan $\mathrm{Ma}^{1}$, Zhenyi Kong ${ }^{1}$, Yonghui $\mathrm{Li}^{1,2^{*}}$, Xiaogu Zhang ${ }^{3}$, Shuichi Hokoi ${ }^{1}$, and Xiuzhang Fu ${ }^{1}$ \\ ${ }^{1}$ School of Architecture, Southeast University, China \\ ${ }^{2}$ Key Laboratory of Urban and Architectural Heritage Conservation of Ministry of Education \\ (Southeast University), Southeast University, China \\ ${ }^{3}$ Department of Architectural heritage, the Palace Museum, China
}

\begin{abstract}
The Palace Museum in Beijing is a world cultural heritage site. Surviving nearly 600 years, heritage buildings in the Palace Museum have been deteriorated by salting out, exfoliation, cracking and so on. For the purpose of quantitative evaluation on current environment risks and proposing conservation approaches, heat and moisture transfer on buildings was simulated by a numerical model and the West Wind-room in the Hall of Mental Cultivation (Yangxin Dian) in the Palace Museum was taken as example. The results indicated that to reduce freezing-thawing cycles, the indoor temperature should be increased during December to early February. Indoor temperature and humidity should be controlled to a more stable and lower level to decrease the damaging from salt crystallization and hydration. And attention should be paid to more saltingout resulted by evaporation increase in spring and autumn. The results will provide support to environment control of Chinese traditional buildings.
\end{abstract}

\section{Research background}

World cultural heritage the Palace Museum in Beijing was built in the 15th century. West Wind-room is one of main buildings in the Hall of Mental Cultivation (Yangxin Dian) which is a building group located in the west of the Palace Museum. The West Wind-room is 7.9 meters in the east-west, 18.1 meters in the north-south and 7.1 meters high. It has a veranda at the entrance on the east. Around the building, there is an ancient tree on the north side and are walls on west and south sides, as shown in Figure 1. Blue bricks, plaster, woods and soil are main construction materials of Chinese traditional buildings like West Wind-room. In the site investigation, deteriorations were observed on West Wind-room, mainly including salting out, exfoliation and cracking. These deteriorations have negative effects on aesthetic value and structural safety of building heritages.

In-situ observation [1] and aging testing [2] are useful to evaluate the degree of deterioration, but simulation is a more efficient and indirect way. Fluctuation of ambient temperature and humidity is a core factor in the material aging procedures [3]. The application of heat and moisture coupled transfer theory and numerical simulation has obtained some achievements in the fields of historic building energy-saving $[4,5]$ and

'Corresponding author: liyonghui@,seu.edu.cn 
environment control $[6,7]$, and it is becoming an important method in building heritage conservation [8]. This paper aims at quantitative evaluation on current state of West Windroom, and the results will guide the conservation of Chinese traditional buildings in the further step.

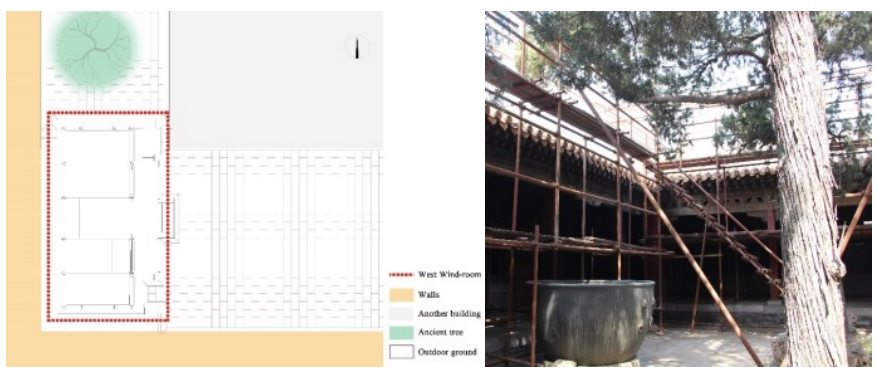

Fig. 1. Plan of West Wind-room and the ancient tree on its north side

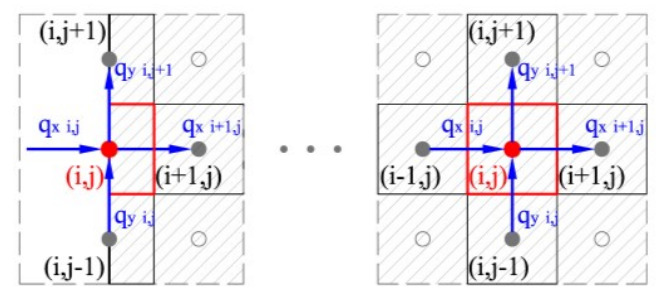

Fig. 2. Heat and moisture flow on building

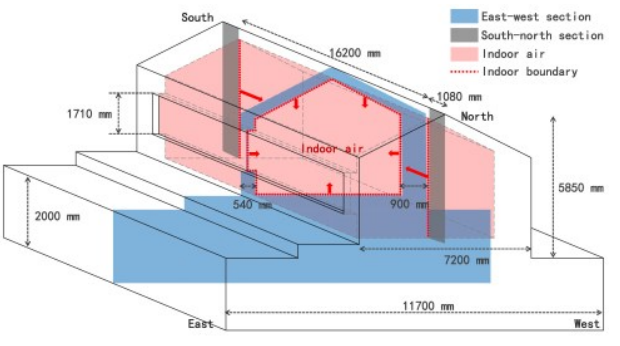

Fig. 3. Simulation model of West Wind-room

\section{Heat and moisture transfer numerical simulation on building envelop}

\subsection{Fundamental equations and methods}

The heat and moisture transfer in the building can be calculated out by equation (1) and (2) [9], which has been proved in previous research [10]:

Heat balance:

$$
c \rho \frac{\partial T}{\partial t}=\frac{\partial}{\partial x}\left[\left(\lambda+r \lambda^{\prime}{ }_{T g}\right) \frac{\partial T}{\partial x}+r \lambda^{\prime}{ }_{\mu g}\left(\frac{\partial \mu}{\partial x}-\mathbf{n}_{\mathbf{x}} g\right)\right]
$$

Moisture balance:

$$
\rho_{w} \frac{\partial \Psi}{\partial \mu} \frac{\partial \mu}{\partial t}=\frac{\partial}{\partial x}\left[\lambda^{\prime}{ }_{T} \frac{\partial T}{\partial x}+\lambda^{\prime}{ }_{\mu}\left(\frac{\partial \mu}{\partial x}-\mathbf{n}_{\mathbf{x}} g\right)\right]
$$

Where, $\mathrm{c}$ is thermal capacity; $\rho$ is density; $\mathrm{T}$ is temperature; $\Psi$ is volumetric moisture content; $\mu$ is water chemical potential; $\lambda$ is thermal conductivity; $\lambda_{T}^{\prime}$ is moisture conductivity due to temperature gradient; $\lambda^{\prime}{ }_{\mu}$ is moisture conductivity due to water chemical potential gradient; $r$ is phase change heat for vaporization; $t$ is time. And the subscript $\mathrm{w}$ means liquid water while $\mathrm{g}$ is gaseous phase.

Based on the equation (1) and (2), the numerical simulation of heat and moisture transfer on heritage buildings is realized by FORTRAN computer language. As Figure 2 shows the heat flow and moisture flow coming into and out from the boundary and internal 
nodes, where the calculated area is divided by the dashed line, and the calculated node is at the intersection of the dashed lines.

\subsection{Modelling of West Wind-room}

Two-dimensional modelling was built considering the two sections ${ }^{\dagger}$ of West Windroom, and the indoor air temperature and relative humidity $(\mathrm{RH})$ were calculated out by adding heat and moisture from both sections, as shown in Figure 3.

Boundary conditions of the model include outdoor air temperature, outdoor air RH, direct and diffused solar radiation, nocturnal radiation, rainfall, air exchange and temperature and moisture content of soil bottom. Data of air temperature, air RH and rainfall in the year 2016 were collected by the weather station in the Palace Museum ${ }^{*}$. The radiation on the building surfaces were calculated based on latitude, longitude and cloud. Soil temperature and moisture content at the soil bottom were measured in-situ.

\section{Results}

\subsection{Model check}

The model was checked by comparing the calculated indoor temperature and RH with the measured values ${ }^{\S}$. As shown in Figure 4, the calculated temperature was almost identical to the measured value. While the check result of calculated humidity was not so good but acceptable at present. The calculated average indoor temperature in August was $27.88{ }^{\circ} \mathrm{C}$ (Celsius degree), higher than the measured value $0.80{ }^{\circ} \mathrm{C}$; the average calculated indoor temperature in November was $5.06{ }^{\circ} \mathrm{C}$, lower than the measured temperature $3.40{ }^{\circ} \mathrm{C}$. The calculated average indoor relative humidity in August was $67.48 \%$, lower than the measured humidity $13.25 \%$, and the calculated humidity in November was $83.53 \%$, higher than the measured value $13.93 \%$.

The differences between calculated values and measured values can be explained as that the indoor air was calculated as one node, and the complexity of indoor air flow was not completely considered.
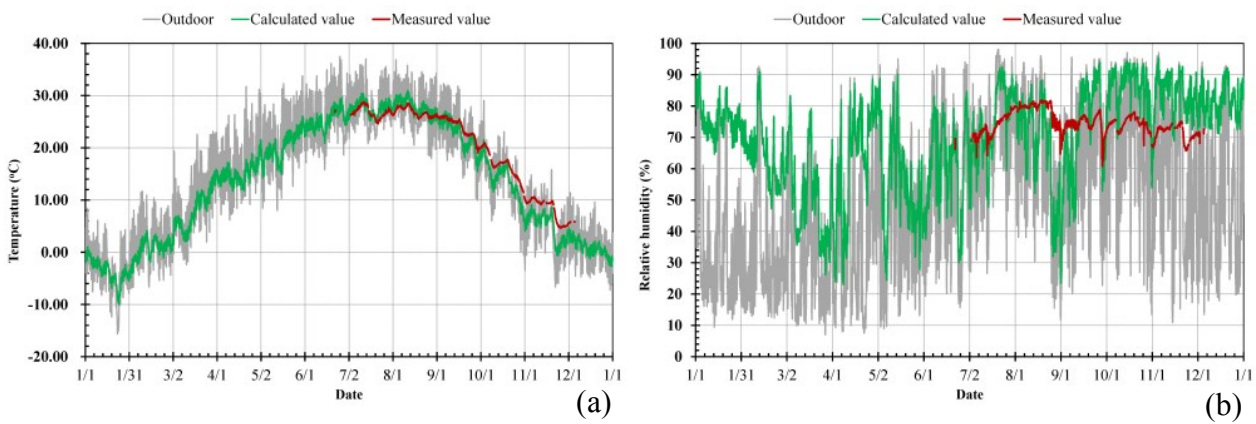

Fig. 4. Results of model check: (a) Air temperature; (b) Air relative humidity

\footnotetext{
$\dagger$ The drawings were provided by Department of Architectural heritage of the Palace Museum.

$\$$ These data were provided by the Department of Architectural heritage of the Palace Museum.

$\S$ Three measure points in the middle part indoor West Wind-room were set by the Department of Architectural heritage in 2016.
} 


\subsection{Building temperature}
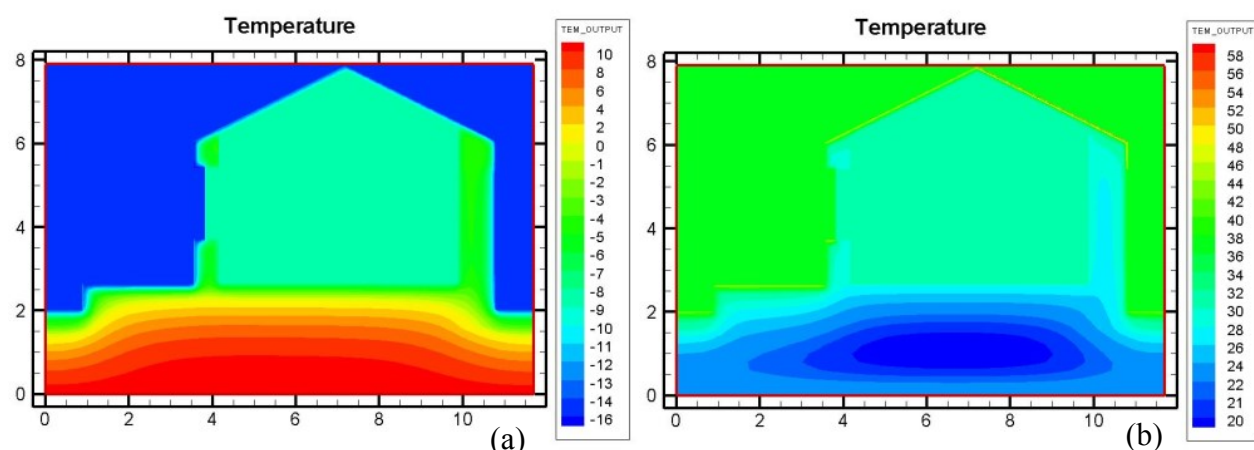

Fig. 5. Building temperature at typical time: (a) January 23th 7:45 with the lowest outdoor temperature; (b) July 10th 14:00 with the highest outdoor temperature

Figure 5 shows the calculated result of building temperature when outdoor air temperature reached the bottom (January 23th, 7:45) and the top (July 10th, 14:00) of the whole year. When the outdoor air temperature was lowest with value of minus $15.69{ }^{\circ} \mathrm{C}$, temperature of the building ranged from $-16.73{ }^{\circ} \mathrm{C}$ to $11.10{ }^{\circ} \mathrm{C}$. And when outdoor air temperature was highest with value of $36.04{ }^{\circ} \mathrm{C}$, temperature of the building ranges from $19.20^{\circ} \mathrm{C}$ to $58.75^{\circ} \mathrm{C}$. The largest value of the building temperature appears on the outdoor surface of the roof due to solar radiation. At the bottom of the east wall, the annual temperature on indoor surface, at internal midpoint and on outdoor surface fluctuated as 13.59 ${ }^{\circ} \mathrm{C} \pm 19.65{ }^{\circ} \mathrm{C}, \quad 14.06{ }^{\circ} \mathrm{C} \pm 19.26{ }^{\circ} \mathrm{C}$ and $14.20{ }^{\circ} \mathrm{C} \pm 30.83{ }^{\circ} \mathrm{C}$ respectively, and temperature at the bottom of the west wall were $13.17{ }^{\circ} \mathrm{C} \pm 19.53{ }^{\circ} \mathrm{C}, 13.15^{\circ} \mathrm{C} \pm 18.05^{\circ} \mathrm{C}$ and $13.04{ }^{\circ} \mathrm{C} \pm 28.69^{\circ} \mathrm{C}$ from indoor to outdoor. The annual surface temperature of indoor floor was $13.09{ }^{\circ} \mathrm{C} \pm 19.37^{\circ} \mathrm{C}$.

Days of temperature below $0{ }^{\circ} \mathrm{C}$ on indoor surfaces of east wall, floor and west wall were 54 days, 57 days and 61days. And on outdoor surfaces of east wall and west wall there were 115 days and 118 days when the surface temperature was below $0{ }^{\circ} \mathrm{C}$.

\subsection{Building moisture content and water evaporation}

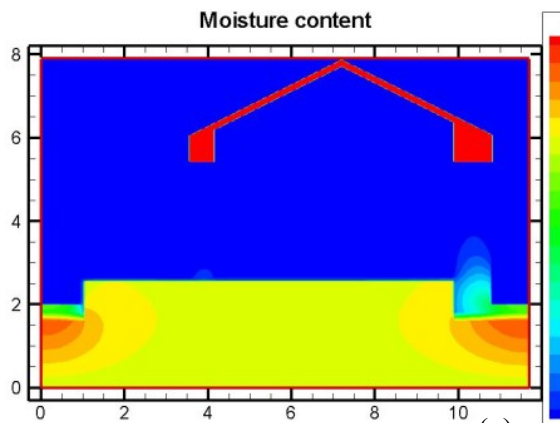

(a)

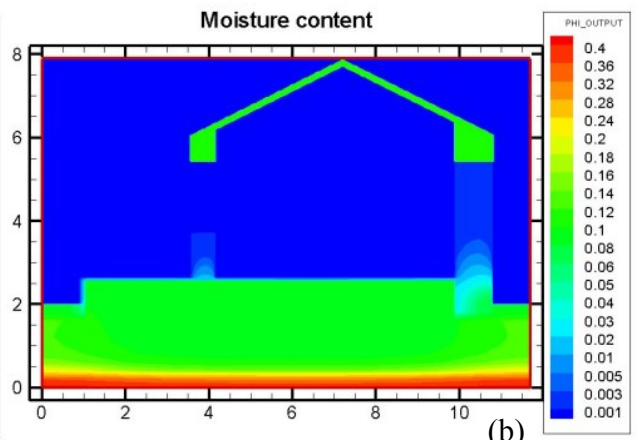

(b)

Fig. 6. Building moisture content at typical time: (a) January 23 th $7: 45$ with the lowest outdoor temperature; (b) July 10th 14:00 with the highest outdoor temperature

Figure 6 shows the calculated moisture content of the building envelops at the same time with Figure 5. At the moment of lowest outdoor temperature, building moisture content ranged from $0.001 \mathrm{~m}^{3} / \mathrm{m}^{3}$ to $0.12 \mathrm{~m}^{3} / \mathrm{m}^{3}$. And in condition of highest outdoor 
temperature, moisture content ranged from $0.002 \mathrm{~m}^{3} / \mathrm{m}^{3}$ to $0.41 \mathrm{~m}^{3} / \mathrm{m}^{3}$. The annual moisture content of indoor surface, internal midpoint and outdoor surface at the bottom of east wall were $0.003 \mathrm{~m}^{3} / \mathrm{m}^{3} \pm 0.003 \mathrm{~m}^{3} / \mathrm{m}^{3}, 0.008 \mathrm{~m}^{3} / \mathrm{m}^{3} \pm 0.005 \mathrm{~m}^{3} / \mathrm{m}^{3}, 0.002 \mathrm{~m}^{3} / \mathrm{m}^{3} \pm$ $0.009 \mathrm{~m}^{3} / \mathrm{m}^{3}$ respectively, and at the bottom of west wall were $0.003 \mathrm{~m}^{3} / \mathrm{m}^{3} \pm 0.005 \mathrm{~m}^{3} / \mathrm{m}^{3}$, $0.017 \mathrm{~m}^{3} / \mathrm{m}^{3} \pm 0.008 \mathrm{~m}^{3} / \mathrm{m}^{3}, 0.017 \mathrm{~m}^{3} / \mathrm{m}^{3} \pm 0.008 \mathrm{~m}^{3} / \mathrm{m}^{3}$ respectively. The moisture content of indoor floor surface was $0.006 \mathrm{~m}^{3} / \mathrm{m}^{3} \pm 0.014 \mathrm{~m}^{3} / \mathrm{m}^{3}$.
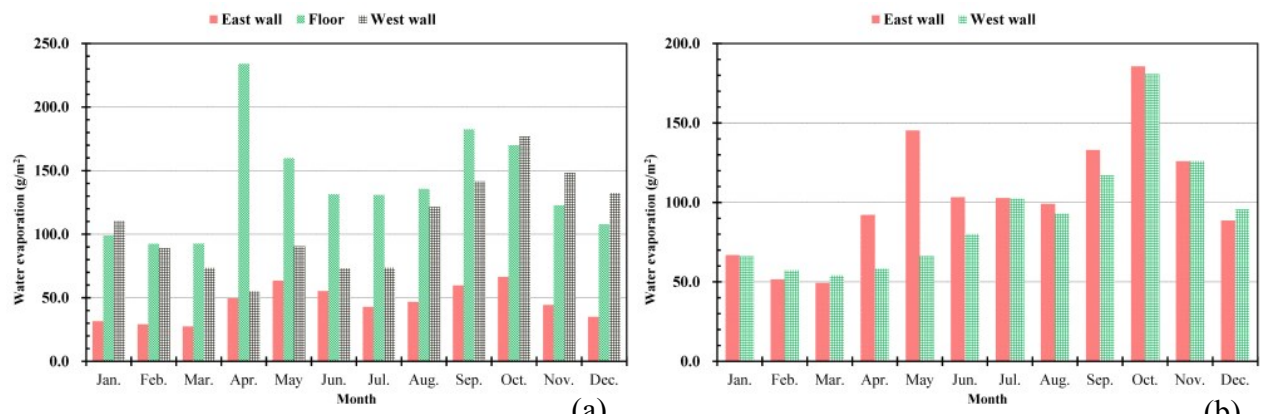

(a)

Fig. 7. Monthly water evaporation on building surfaces for the whole year: (a) indoor surfaces; (b) outdoor surfaces

Figure 7 shows water evaporation from January to December from indoor and outdoor surfaces. There were $27.45 \mathrm{~g} \sim 66.46 \mathrm{~g}, 92.48 \mathrm{~g} \sim 233.93 \mathrm{~g}$ and $55.09 \mathrm{~g} \sim 176.79 \mathrm{~g}$ water evaporating from the indoor surfaces of east wall bottom, floor and west wall bottom per square meter every month. On the outdoor surfaces, monthly evaporation were $49.25 \mathrm{~g}$ $185.64 \mathrm{~g}$ and $91.88 \mathrm{~g} \sim 238.64 \mathrm{~g}$ at bottoms of east wall and west wall respectively.

\section{Discussing}

\subsection{Risk related to building temperature}

The temperature fluctuation of outdoor surfaces is 1.5 times of indoor surfaces at the bottom of walls. Compared with the surface temperature, the temperature inside the wall have a thermal delay. The temperature difference between the outdoor surface and the indoor surface is $0.21{ }^{\circ} \mathrm{C}$ at the bottom of east wall and $0.13{ }^{\circ} \mathrm{C}$ at the bottom of west wall. This is because the direct solar radiation on the west wall is shaded.

Freezing-thawing cycles occur more easily on the outdoor wall surfaces than indoor according to days of temperature below $0{ }^{\circ} \mathrm{C}$, and the number of risk days of outdoor surfaces is near 2 times of indoor. Inside the building, west wall surfaces have more risk of freezing-thawing cycles than east wall and floor surface. This is also because of the less solar radiation on west wall and the large heat capacity of the rammed earth foundation under the floor.

\subsection{Risk related to building moisture content}

Moisture content of the internal midpoint is 2 to 8 times the surfaces in walls, and the fluctuation of moisture content inside the wall also has a delay. Moisture content of the earth foundation under West Wind-room is much higher than that of indoor floor.

The water evaporation from indoor surface of the east wall is half of the west wall and floor. Evaporation from outdoor walls are almost the same. The water evaporation from 
both indoor and outdoor surfaces will increase in spring (from April to May) and autumn (from September to October). More evaporation means more possibilities of salting-out. The decrease in winter is due to temperature decrease, and in summer is because that indoor humidity becomes much higher.

\subsection{Risk of salt damaging}

Soluble salt may hydrate or crystallize under different temperature and relative humidity conditions. The salt volume increase during this procedure damages the pores in building materials. For example, the sodium sulfate changes between mirabilite, solution and thenardite and the dotted lines in Figure 8 are the boundary of form change [11]. As shown in Figure 8(a), there are more possibilities of salt hydration from March to April and from July to October on indoor wall and floor surfaces.

Figure 10(b) reflects the possibilities of sodium sulfate damaging at $3 \mathrm{~cm}$ below the indoor wall surfaces and $1.5 \mathrm{~cm}$ below indoor floor surface. There are more risks of salt hydration damaging below indoor wall surfaces from July to November. And below indoor floor, salt hydration damaging is more likely occur from October to December.
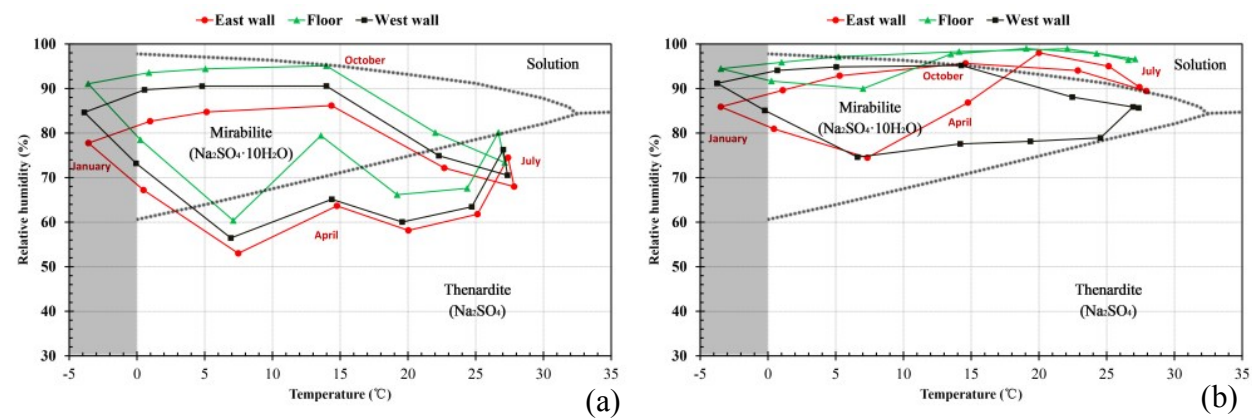

Fig. 8. Salt hydration and crystallization damaging risk: (a) indoor surfaces; (b) below indoor surfaces

\section{Conclusion}

For the final purpose of proposing environment control methods and realize preventive conservation for buildings in the Palace Museum, West Wind-room was taken as the research object. The temperature and moisture content on it were numerically calculated and related to deterioration in current state.

Indoor temperature needs to be increased during December to early February to reduce freezing-thawing cycles on indoor surfaces. Attention should be paid to more serious salting-out resulted by water evaporation increase in spring and autumn. Indoor temperature and humidity need to be controlled to a more stable and lower level, in order to decrease the damaging from salt hydration.

This work is supported by National Natural Science Foundation of China (51878140) and Natural Science Foundation of Jiangsu Province (BK20161424). Thanks for the Department of Architectural heritage of the Palace Museum and the Research Conservation for the Hall of Mental Cultivation (Yangxin Dian) Project of the Palace Museum. 


\section{References}

1. H. Morillas, C. García-Florentino, I. Marcaida, M. Maguregui, G. Arana, L.F.O. Silva, J.M, Spectrochim. Madariaga. Acta - Part B At. Spectrosc. (2018).

2. Y. xia Shen, W. wu Chen, J. Kuang, W. fei Du, J. Cent. South Univ. 24 (2017) 796806.

3. Z. Zhang, J. Eng. Geol. 25(3) (2017)

4. S. Liuzzi, C. Rubino, P. Stefanizzi, A. Petrella, A. Boghetich, C. Casavola, G. Pappalettera , Constr. Build. Mater. 158 (2018) 24-32.

5. X. Liu, Y. Chen, H. Ge, P. Fazio, G. Chen, Energy Build. 93 (2015) 259-268.

6. M.Y. Ferroukhi, R. Djedjig, R. Belarbi, K. Limam, K. Abahri, Energy Procedia. 78 (2015) 2584-2589.

7. M. Qin, G. Walton, R. Belarbi, F. Allard, Energy Convers. Manag. 52 (2011) 14701478.

8. W. Araoka, S. Hokoi, D. Ogura, C. Iba, Y. Li, S. Hu, in: Energy Procedia, 2017.

9. M. Matsumoto, S. Hokoi, M. Hatano, Build. Environ. 36 (2001) 733-742.

10. Y. Li, D. Ogura, S. Hokoi, J. Wang, T. Ishizaki, J. Asian Archit. Build. Eng. (2014) 499-506.

11. R.J. Flatt J. Cryst. Growth. 242 (2002) 435-454. 